\title{
GOVERNANÇA URBANA EMPREENDEDORISTA E MEGAEVENTOS ESPORTIVOS ${ }^{1}$
}

\section{ENTREPRENEURIAL URBAN GOVERNANCE AND MEGA-SPORTING EVENTS}

\begin{abstract}
Demian Garcia Castro
Licenciado e bacharel em Geografia (UERJ), especialista em Sociologia Urbana (UERJ), mestre em Geografia (UERJ), mestre em Engenharia Urbana (UFRJ), doutorando em Geografia (UERJ)

Professor do Colégio Pedro II

demiancastro@yahoo.com.br
\end{abstract}

\section{Resumo}

Este artigo busca compreender as relações existentes entre o modelo de governança urbana empreendedorista, que possui como uma das principais características a realização de grandes projetos de intervenção urbana, e os megaeventos esportivos. Neste contexto, é desenvolvida uma análise da nova governança urbana empreendedorista; a seguir, os megaeventos esportivos são apresentados como uma estratégia desse modelo de governança; por fim, é feita uma recuperação da trajetória dos Jogos Olímpicos, a partir da qual procura-se destacar sua transformação em uma grande marca, objeto de interesse de grandes empresas e de disputa de governantes das principais cidades do mundo.

Palavras-chave: Empreendedorismo urbano; Megaeventos esportivos; Jogos Olímpicos.

\section{ABSTRACT}

This article seeks to understand the relationship between the model of entrepreneurial urban governance, which has one of the main features to make large projects of urban intervention, and the mega-sporting events. In this context, the entrepreneurial urban governance analysis has been developed. Then, the mega-sporting events are presented as a key role in strategy of this governance model and, finally, the article will also present the Olympic Games historical highlighting its transformation into a major brand. Moreover, large companies and the governments of the major cities around the world dispute the Olympic Games as regards to the major brand.

Keywords: Entrepreneurial urban governance; Mega-sporting events; Olympic Games. 


\section{A nova governança urbana empreendedorista}

Desde a década de 1980, o Estado brasileiro vem passando por grandes modificações políticas e institucionais. Dentre elas destacam-se a redemocratização, a nova Constituição promulgada em 1988 e a implementação de reformas estruturais baseadas em princípios neoliberais.

A partir da Constituição de 1988, os municípios passaram a ser considerados "entes administrativos", recebendo diversas responsabilidades que anteriormente cabiam ao Governo Federal. Esse processo de descentralização pode ser associado a uma negação do centralismo político de anos de governo autoritário, porém, ao alterar o sistema de decisões políticas municipais, bem como o escopo da atuação dos agentes vinculados a essa escala da política, é possível alinhar o fortalecimento do poder local às transformações associadas à globalização e à implementação de reformas estruturais, de cunho neoliberal, em curso em diversos países.

Com a crise do modo fordista de produzir, ganhou expressão, na década de 1970, um processo de reestruturação produtiva com a emergência de um padrão de acumulação flexível, baseados, nas mudanças de padrão tecnológico, na flexibilização do trabalho, e, também, na constituição de uma Nova Divisão Internacional do Trabalho, com a relocalização espacial das plantas produtivas (HARVEY, 1992).

No bojo da crise do fordismo, entra em crise também o modelo do Estado do Bem Estar, que se difundira por mais de trinta anos na Europa Ocidental em decorrência das lutas trabalhistas e também da forte presença dos ideários socialistas enquanto alternativa de sistema político e econômico. Ao final da década de 1970 e início da década de 1980, a eleição dos governos liberais-conservadores de Margaret Thatcher (primeira ministra do Reino Unido entre 1979 e 1990) e Ronald Reagan (presidente dos EUA de 1981 a 1989) trouxe para a agenda política concepções neoliberais de Estado, enunciadas como única solução para a crise que estava em curso. Nesse contexto ficou famosa a frase de Thatcher: "there is no alternative".

A adoção de políticas desregulacionistas por esses governos anglo-saxões, aliadas ao processo de globalização financeira, forçou os governos dos países periféricos a um ajustamento econômico, imposto através do controle do mercado 
financeiro. Dessa forma, como reforça Fiori (2001), as ideias neoliberais se transformaram em "pensamento único" ao conquistar a mídia e diversos intelectuais de diferentes países que se submeteram a essas novas regras econômicas. Fiori (2001) afirma que na década de 1990 o neoliberalismo se transformou em "um novo senso comum, quase 'ensurdecedor' [...] sintetizado por algumas palavras de ordem: menos Estado, fim das fronteiras, desregulação dos mercados, equilíbrio físcal, competitividade global etc." (FIORI, 2001, p.74-75).

O Estado-nação, por um lado, reduziu seu papel nas atividades econômicas, com a privatização de empresas estatais e das infraestruturas nacionais, e nas políticas sociais. Entretanto, assumiu um novo papel de agente regulador da economia e dos serviços públicos. Por outro lado, ocorreu uma valorização do governo local visto como capaz de dar respostas rápidas aos desafios da globalização. Para Oliveira (1998 apud SANTOS JUNIOR, 2001), o Estado foi reduzido apenas no tocante às suas funções sociais, pois permaneceu responsável pela reprodução do capital.

Dessa forma, as reformas institucionais que derivaram na descentralização administrativa, com a municipalização das políticas públicas, possibilitaram o estabelecimento de novas estruturas organizacionais do poder local, principalmente vinculadas às parcerias entre o setor público e o setor privado. O Estado do Bem Estar distributivista, pautado em padrões universalistas, foi substituído pela ideia de "bom governo", no qual o qualificativo relaciona-se a sua capacidade de integrar o espaço de forma competitiva aos mercados globais (SANTOS JUNIOR, 2001).

O debate sobre a inserção das cidades no mapa dos fluxos da globalização muda as discussões sobre os problemas urbanos, que, nessa ótica, passam, por exemplo, a não mais serem vinculados ao "crescimento desordenado, reprodução da força de trabalho, equipamentos de consumo coletivo, movimentos sociais urbanos, racionalização do uso do solo" (VAINER, 2000, p. 76). Nesse contexto, Santos Junior (2001) afirma que:

No novo modelo, o eixo de análise se desloca para a produtividade urbana, e a identificação dos obstáculos, para a inserção competitiva das cidades nos circuitos globais. As funções do poder público também se deslocam: as da gestão e do planejamento da cidade, para a garantia de um meio ambiente favorável aos negócios e ao desenvolvimento econômico. (p. 34-35)

Essa nova forma de governança das cidades vem sendo denominada de "empreendedorismo urbano" (HARVEY, 2005). Porém, antes de tecer maiores

Geo UERJ - Ano 15, no. 24, v. 1, $1^{\circ}$ semestre de 2013 p. 37-60

ISSN: 1415-7543 E-ISSN: 1981-9021

http://www.e-publicacoes.uerj.br/index.php/geouerj 
comentários sobre essa nova governança, é importante caracterizar o que se entende por governança.

A ideia de governança, tal qual a de governabilidade, emergem no contexto de implementação das políticas neoliberais. A palavra governabilidade, em sua concepção mais simples, quer dizer tornar governável, em contraposição a uma pretensa ingovernabilidade que existiria antes, resultado do excesso de demandas sociais e das resistências às reformas neoliberais. Assim, a palavra já apresenta consigo um diagnóstico conservador da crise, ao mesmo tempo em que traz a sua solução: as reformas estruturais (FIORI, 1995). Nesse mesmo sentido, a palavra governança está, no seu sentido neoliberal original, atrelada à concepção de "bom governo", ou seja, à capacidade do Estado de ser governo, sem qualquer ênfase na sua relação com a sociedade, retirando o seu sentido politico e reforçando o seu sentido técnico.

Santos Junior (2001, p.60) acredita na possibilidade de reconceituação do termo governança, que passaria a ser "entendida como a interação entre governo e sociedade, com análises centradas na questão dos arranjos institucionais que coordenam e regulam a relação entre o governo e os atores sociais dentro de um sistema político”. O sentido de governança se deslocaria da análise do Estado em si, para a relação entre a sociedade civil e o Estado, sugerindo que a capacidade de governar não está vinculada somente às instituições formais, mas também às relações de cooperação e conflitos dos diferentes agentes sociais. Nesse sentido, Harvey (2005) reforça que a ideia de governança urbana é muito mais ampla do que a de governo urbano e que o poder de organização da vida urbana está "numa coalização de forças mais ampla em que o governo e a administração urbana desempenham apenas papel facilitador e coordenador. O poder de organizar o espaço se origina em um conjunto complexo de forças, mobilizado por diversos agentes sociais." (HARVEY, 2005, p.171).

Harvey (2005) indica que a abordagem empreendedora surgiu nas décadas de 1970 e 1980 no lugar de uma abordagem administrativa característica da década de 1960. Esse corte temporal reforça o papel desempenhado pela ascensão do empreendedorismo urbano na transição geral do capitalismo de um regime de acumulação fordista-keynesiano para um regime de "acumulação flexível". 
A principal característica desse modelo de governança são as "parcerias públicoprivadas", a partir das quais os empresários integram-se a busca de fontes externas de financiamento e investimentos, justificadas como respostas à crise fiscal. Por conta dessas parcerias, os projetos de desenvolvimento urbano passam a ser especulativos, ou seja, sujeitos a riscos. As análises empíricas mostram que os riscos são assumidos pelo setor público enquanto que o setor privado costuma ficar com os benefícios. Outra característica, consequência das anteriores, é que os projetos passam a ter um caráter pontual, cujo foco incide sobre as partes do território associadas aos interesses privados, normalmente vinculados a empreendimentos imobiliários e a espaços de consumo. Assim, o planejamento e a gestão do território passam de um paradigma racional, totalizante, para um especulativo, pontual.

Vainer (2000) aponta que essa linha de argumentação passa a ser encarada como "único meio eficaz para fazer frente às novas condições impostas pela globalização às cidades e aos poderes locais" (VAINER, 2000, p.78). O "pensamento único" neoliberal também se impõe na gestão e no planejamento da cidade, estabelecendo um novo paradigma: a governança empreendedorista urbana.

A gestão das cidades passa, cada vez mais, a se parecer com a gestão das empresas, incorporando os princípios de agilidade e flexibilidade para adaptar-se ao mundo dos negócios. Segundo Vainer (2000, p.76), esse modelo, “inspirado em conceito e técnicas oriundos do planejamento empresarial, originalmente sistematizados na Havard Business School", deveria ser adotado pelas cidades pelo fato das mesmas estarem submetidas aos mesmos desafios das empresas.

Nessa argumentação, a cidade, agora cidade-empresa, é transformada em sujeito do processo, o que levou Borja \& Castells, dois intelectuais internacionais de grande prestígio, a afirmarem que "as cidades são as multinacionais do século XXI" (1997 apud VAINER, 2000). É essa argumentação que permite a transposição das ideias de competitividade e produtividade, a partir da qual a cidade é subordinada ao mercado, para a governança das cidades. Para Vainer, “[...] ver a cidade como empresa significa, essencialmente, concebê-la e instaurá-la como agente econômico que atua no contexto de um mercado e que encontra neste mercado a regra e o modelo do planejamento e execução de suas ações." (VAINER, 2000, p. 86).

\footnotetext{
Geo UERJ - Ano 15, no. 24, v. 1, $1^{\circ}$ semestre de 2013 p. 37-60 ISSN: 1415-7543 E-ISSN: 1981-9021 http://www.e-publicacoes.uerj.br/index.php/geouerj
} 
A visão reificada de cidade, que a considera como agente ativo do desenvolvimento político e econômico, sobrepõe-se à visão de cidade como espaço de lutas entre diferentes agentes pela apropriação material e simbólica do espaço urbano. Ao pensar a cidade como um agente, naturalizam-se interesses de determinados agentes hegemônicos, que passam a ser vistos como interesses da cidade. Por exemplo, os investimentos pontuais que o poder público realiza no espaço urbano favorecendo a ação dos incorporadores são vistos como interesses da cidade (HARVEY, 2005). A cidade como agente, tornada cidade-empresa, desliza para cidade-empresários. (VAINER, 2000).

A representação da cidade-sujeito coexiste com a representação cidade-objeto. A cidade-empresa coloca à venda a cidade-mercadoria. Nessa concepção, segundo Arantes (2000), a cidade não deve ser gerida "like a business", mas “for business". Mas quem são os compradores da cidade? O que eles buscam? O que a cidade oferece a seus compradores? A venda da cidade é estabelecida a partir de grandes estratégias de marketing urbano, acompanhada de uma política de image-making, para a sua inserção no mercado global. Nesse sentido, a dimensão simbólica das cidades associadas à cultura, aparece como capaz de oferecer distinção às cidades na atração por investimentos (ARANTES, 2000).

Este conteúdo simbólico vem sendo apropriado por agentes econômicos que acumulam lucro, prestígio e poder com a permanente construção, destruição e venda de imagens da cidade (RIBEIRO, 2006). A manipulação das linguagens simbólicas, associadas a essa estetização do poder, reflete nas escolhas sobre quem, ou o que, pode estar visível na paisagem (ARANTES, 2000). Nessa concepção, a cidade é vista, obviamente, como valor de troca, sobrepondo-se aos interesses daqueles que a veem cotidianamente como valor de uso.

A cidade enquanto valor de troca, cidade-mercadoria, é qualificada a partir de demandas de localizações associadas ao mercado externo, ou seja, ao capital transnacional. Este estaria interessado em atributos específicos das cidades: espaços de convenções, parques industriais, centros históricos, áreas portuárias, parques temáticos de lazer, condomínios fechados, megaeventos, etc. Dessa forma, Vainer (2000) reforça 
que todas as cidades devem vender a mesma coisa, pois os possíveis compradores possuem as mesmas necessidades.

Ferreira (2011) argumenta que esse processo tem levado a certa banalização do espaço, pois a produção do espaço urbano, derivada da competição interurbana pela atração de fluxos globais, estaria realizando-se baseada na cópia de "modelos de sucesso internacional", tais como os citados no parágrafo anterior. Assim, cidades localizadas em diferentes partes do planeta passam a ter muitas características semelhantes.

Percebe-se que os compradores da cidade-mercadoria são o capital internacional e os visitantes solváveis. A cidade transformada em coisa, não é uma mercadoria qualquer, mas, sim, uma mercadoria de luxo (VAINER, 2000). Segundo Vainer (2000), a cidade como sujeito e objeto de negócios nega radicalmente o espaço político, de conflitos e disputas ideológicas entre os agentes. Como a cidade passa a ser encarada como um agente, empresa multinacional, os interesses estabelecidos como sendo da cidade, são naturalizados. A cidade competitiva precisa da união de todos os seus habitantes para sair da crise e para oferecer paz e estabilidade ao capital internacional e aos visitantes estrangeiros. Daí emerge a cidade-pátria, onde impera o consenso e onde são reforçadas as identidades territoriais.

Entretanto, as especificidades da urbanização brasileira apontam que a inserção da acumulação urbana nos circuitos financeiros globalizados ocorre mantendo parcialmente o padrão de modernização-conservadora característico da sua história urbana. Resultando, portanto, em uma governança empreendedorista com traços muito particulares, pois, ao mesmo tempo em que transforma a cidade em mercadoria a ser vendida no mercado global, mantém práticas patrimonialistas de acumulação urbana e de representação política baseada no clientelismo. (RIBEIRO \& SANTOS JUNIOR, 2011).

Para Ribeiro e Santos Junior (2011), a permanente crise do capitalismo financeirizado e o ciclo de prosperidade e estabilidade que o Brasil vem atravessando, aliado à existência de ativos urbanos passíveis de espoliação, ou seja, comprados a preços baixos e vendidos no mercado mundial, têm inserido as cidades brasileiras nos circuitos internacionais de acumulação. 
Assim, as disputas e as relações de dominação e poder entre os agentes sociais urbanos na cidade do Rio de Janeiro vêm configurando uma nova coalizão de forças locais, em aliança com antigas coalizões dominantes (caracterizadas pelo localismo, paroquialismo e clientelismo), envolvendo inclusive, ainda que de forma minoritária, os segmentos populares e progressistas, em torno da governança empreendedorista. Essa nova coalizão de forças seria sustentada por frações do capital imobiliário em aliança com frações do capital financeiro e estaria vinculada a algumas formas específicas de intervenção na cidade, com destaque para a reestruturação das áreas centrais e a realização de megaeventos (SANTOS JUNIOR \& SANTOS, 2011).

\section{Os megaeventos esportivos como estratégia da governança urbana empreendedorista}

Buscando fazer uma síntese dos principais elementos relacionados à governança urbana empreendedorista analisados na seção anterior, apresenta-se a Figura 1, elaborada por Sánchez et al. (2004). No esquema apresentado, ressalta-se a importância conferida aos grandes projetos de desenvolvimento urbano, entre os quais estão os megaeventos esportivos. 


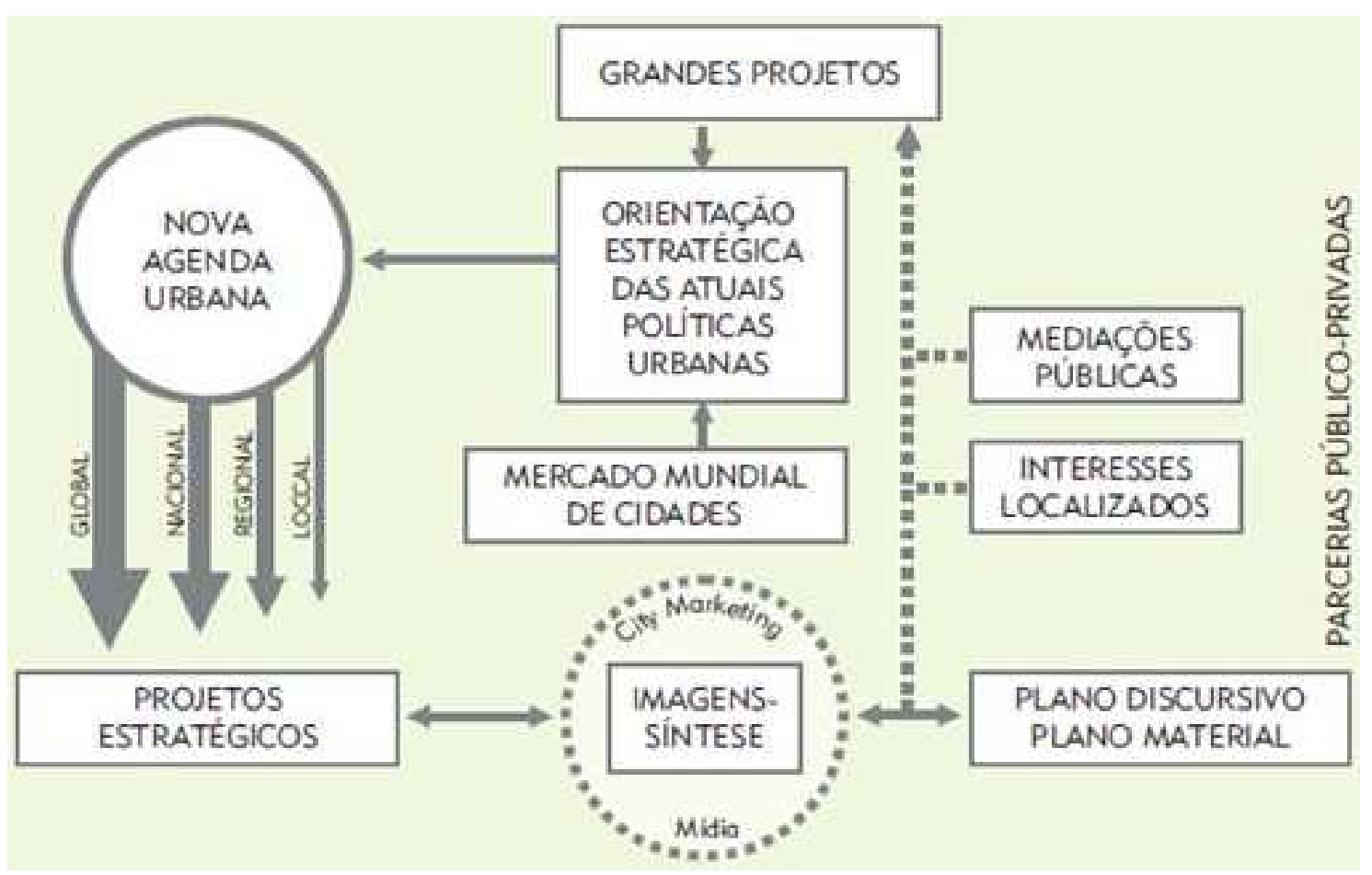

Figura 1 - Organograma dos principais elementos da governança urbana empreendedorista

Fonte: Sánchez et al. (2004).

Sánchez et al. (2004) reforçam a importância dos Grandes Projetos de Desenvolvimento Urbano (GPDUs) como uma das principais estratégias adotadas pelas cidades (tornadas sujeitos) em busca de crescimento econômico e de competitividade. Muitas são as expectativas e os exemplos de GPDUs orientados para a "revitalização urbana" e para a atração tanto de turistas quanto de investimentos estrangeiros em resposta à crise fiscal e às desigualdades sócio-espaciais.

Entre as intervenções urbanas de grande porte, têm se destacado, pela recorrência, como modelo de sucesso e de banalização do espaço, as intervenções em áreas portuárias (frentes marítimas ou ribeirinhas), os projetos de renovação das áreas centrais e os projetos de reestruturação urbana baseados na atração de eventos internacionais de grande porte, principalmente os esportivos, foco do presente trabalho.

Roche (2001 apud ALMEIDA et al., 2009) define megaeventos (comerciais e esportivos), a partir da escala cultural, da carga dramática, do apelo popular e da significância internacional, destacando também o alcance de mídia e de mercado desses eventos. 
Os Jogos Olímpicos, além de grande apelo de mídia e de mercado internacional, se caracterizam como o evento esportivo que possui maior poder de transformação da paisagem das cidades, alterando as formas, as funções e a dinâmica territorial. Mascarenhas (2004) destaca que as instalações esportivas além de apresentarem um aspecto durável, decorrente do alto investimento em capital fixo, e ampla visibilidade, muitas vezes passam a se constituir em importantes centralidades física e simbólica no interior do espaço urbano.

Os Jogos Olímpicos se apresentam no imaginário coletivo como metáfora das desigualdades do cenário internacional e vitrine das potências econômicas, políticas e tecnológicas, o que é evidenciado tanto pelo desempenho olímpico, expresso no quadro de medalhas, quanto pela realização dos Jogos. De 26 edições dos Jogos Olímpicos, 14 foram realizadas na Europa Ocidental, enquanto os Estados Unidos foram o país onde o evento aconteceu mais vezes, em um total de quatro edições.

Nenhuma edição foi realizada no continente africano e no sul-americano. Isso deixará de ser verdade, em breve, com a realização dos Jogos Olímpicos de 2016, na cidade do Rio de Janeiro. Esse fato está relacionado ao papel político e econômico que o Brasil vem desempenhando no cenário internacional.

A partir do que foi considerado acima, pode-se afirmar que existe uma lógica espacial da realização dos Jogos Olímpicos, visualizada na Figura 2.

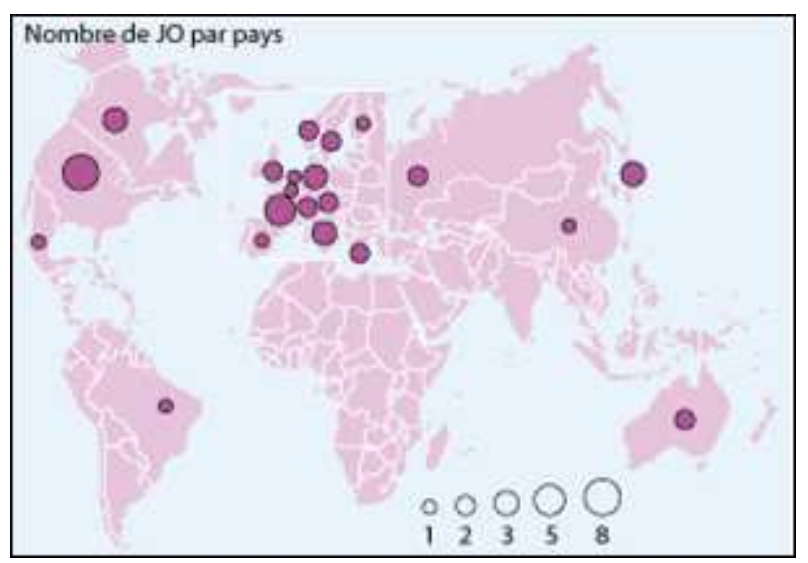

Geo UERJ - Ano $15, \mathrm{n}^{\circ} .24$, v. $1,1^{\circ}$ semestre de 2013 p. 37-60 ISSN: 1415-7543 E-ISSN: 1981-9021 http://www.e-publicacoes.uerj.br/index.php/geouerj 
Figura 2 - Mapa do número de Jogos Olímpicos realizados em cada país (1896-2016) Fonte: La documentation francaise, 2010.

Os Jogos Olímpicos da Era Moderna foram realizados pela primeira vez no ano de 1896, sob idealização de Pierre de Coubertin. As Olimpíadas modernas estão divididas em Jogos de Verão e Jogos de Inverno, a periodicidade é de quatro em quatro anos, como na antiguidade, alternando a cada dois anos entre os Jogos de Verão e de Inverno.

A recriação do movimento olímpico nesse período relaciona-se a expansão de organizações que tinham por objetivo a promoção da paz. Dessa forma, Pierre de Coubertin desejava criar, a partir do esporte, uma forma racionalizada dos conflitos entre os países e promover a confraternização entre as nações em oposição às guerras (RUBIO, 2010). Cabe lembrar que para os gregos, as olimpíadas representavam um momento de trégua nos conflitos para que os competidores e os espectadores pudessem chegar com segurança até Olímpia.

Ao analisar a história de mais de um século de existência do movimento olímpico, tornar-se nítida a relação dos Jogos com as mudanças políticas e sociais mundiais que ocorreram, como, por exemplo, a ascensão do nazismo, a $2^{\text {a }}$ Guerra Mundial (1939-1945) e a Guerra Fria (1945-1991), apesar de o movimento se declarar como apolítico.

Cabe também ressaltar as transformações urbanas associadas aos Jogos Olímpicos, especialmente aos Jogos Olímpicos de Verão, pois, como lembra Mascarenhas (2011), a realização de tal evento demanda: dotar as cidades de instalações, dentro de padrões internacionais, para que possam abrigar a prática de diversas modalidades esportivas; criar condições de alojamento para os atletas, técnicos, imprensa e membros do comitê olímpicos; bem como expandir e/ou aperfeiçoar a infraestrutura urbana. Sem dúvida alguma, a realização de um evento de tal porte se consagra como um momento chave das transformações na paisagem de uma cidade.

Observa-se, no entanto, que, nem sempre o evento se configurou de forma tão expressiva. As primeiras realizações dos Jogos Olímpicos (1896-1904) deixaram poucas marcas na paisagem das cidades-sede. Os Jogos não tinham apoio dos governos nacionais e o número de participantes era reduzido, basicamente descendentes da 
aristocracia europeia e norte-americana que possuíam dinheiro suficiente para se dedicar ao esporte, pois o amadorismo era condição para participação. Devido à falta de apoio, uma das formas encontradas pelos organizadores foi realizar os Jogos juntamente com as Exposições Internacionais. Dessa forma, as três primeiras edições dos Jogos foram marcadas por um verdadeiro desprezo ao movimento olímpico (RÚBIO, 2010).

Ao analisar a história dos Jogos Olímpicos, percebe-se que o evento foi aumentando gradativamente a sua escala de abrangência, o seu nível de organização e a sua capacidade de realizar impactos na infraestrutura urbana, conforme apresentado na Tabela 1, traduzida e adaptada do texto de Essex \& Chalkley (2004).

Tabela 1 - Periodização dos Jogos Olímpicos associada às mudanças de impactos na infraestrutura das cidades-sede (1896-2008)

Periodização Mudanças de impactos na infraestrutura das cidades-sede

Fase 1: 1896-1904

Fase 2: 1908-1932

Fase 3: 1936-1956

Fase 4: 1960-2008
- Pequena escala

- baixo nível de organização

- sem necessariamente acarretar algum novo desenvolvimento

- pequena escala

- maior nível de organização

- envolvendo a construção de instalações esportivas específicas

- grande escala

- alto nível de organização

- envolvendo a construção de instalações esportivas específicas com algum impacto na infraestrutura urbana

- grande escala

- alto nível de organização

- envolvendo a construção de instalações esportivas específicas com significativo impacto na infraestrutura urbana

Fonte: Essex \& Chalkley (2004). Traduzido e adaptado pelo autor.

A partir dos Jogos Olímpicos de 1908, em Londres (Reino Unido), os organizadores começaram a trabalhar com mais antecedência para arrecadar verbas para a construção de instalações esportivas e para a divulgação do evento, que também passou a contar com um público maior.

Já nos Jogos de Los Angeles (EUA), em 1932, pode-se falar em "urbanismo olímpico". No contexto pós-crise de 1929, os Jogos renderam lucros de mais de US\$ 1 
milhão de dólares aos seus organizadores, que levaram o padrão da produção cinematográfica de Hollywood, já reconhecido à época, para a produção dos Jogos (RÚBIO, 2010). Nessa edição também foi edificada a primeira vila olímpica com característica de habitação permanente e não mais de dormitórios, uma característica distintiva dos eventos anteriores (MASCARENHAS, 2011).

Outro momento importante da história dos Jogos foi em Berlim (Alemanha), em 1936. Adolf Hitler fez grandes investimentos na organização do evento e na preparação dos atletas. Seu objetivo era fazer uma propaganda do governo nazista através do esporte. Os Jogos, mais uma vez, mostraram-se rentáveis, além de terem colaborado para o fortalecimento da imagem de Hitler tanto na Alemanha quanto no exterior.

A periodicidade dos Jogos foi interrompida pela deflagração da $2^{a}$ Guerra Mundial, que acabou acarretando o cancelamento das edições de 1940 e 1944. Na edição de Londres, em 1948, por conta das dificuldades financeiras decorrentes da reconstrução do país no pós-guerra, foram utilizadas instalações militares e escolares para a realização dos Jogos. Por outro lado, as edições seguintes, de Helsink (Finlândia), em 1952, e Melbourne (Austrália), em 1956, incorporaram demandas sociais de infraestrutura, transporte e, inclusive grandes projetos habitacionais (MASCARENHAS, 2011).

No contexto de crescimento da organização, dos investimentos e, portanto, da visibilidade dos Jogos, a edição de Roma (Itália), em 1960, apresentou duas grandes novidades: a construção de uma vila olímpica com instalações modernas e o início das transmissões por rádio e televisão. O início das transmissões televisivas se tornou um importante marco na história dos Jogos Olímpicos, pois passou a lhes conferir a condição de megaevento global.

Na edição de 1964, o governo japonês desejava mostrar ao mundo que havia superado a derrota na $2^{\mathrm{a}}$ Guerra Mundial. Em Tóquio, os Jogos além de terem sido repletos de inovações tecnológicas, serviram para reconquistar uma área que estava sendo usada como base militar pelos EUA, com o pretexto da necessidade de instalar, naquele local, a vila olímpica. (MASCARENHAS, 2011)

Em 1968, pela primeira vez os Jogos foram realizados em uma cidade de um país periférico, a Cidade do México (México). Se, por um lado, houve uma série de 
questionamentos provenientes de países ricos sobre os Jogos serem realizados em um país pobre, por outro, deles emergiram apoio e o discurso sobre a importância da difusão do movimento olímpico e dos seus ideais originais de promover a união entre nações (RÚBIO, 2010).

Entretanto, os contrastes entre a quantidade de recursos financeiros investidos e as condições de pobreza do país sede, geraram manifestações populares contra os gastos excessivos e a corrupção. O governo respondeu brutalmente as manifestações. Raeder (2011) relata que dez dias antes da abertura dos Jogos ocorreu um massacre de manifestantes na Plaza las Tres, em Tlatelolco, na Cidade do México. Algumas fontes apontam para mais de mil mortos, apesar das fontes governamentais relatarem quatro mortos e vinte feridos.

Melo \& Gaffney (2010) destacam que, se a edição de 1960 marcou o início da difusão e comercialização global dos Jogos, a edição de 1968 foi a primeira exposição, nessa mesma escala, dos conflitos sociais e, principalmente, da violência praticada contra as classes populares no contexto de mercantilização do evento.

Cabe destacar também a decisão do Comitê Olímpico Internacional (COI) por realizar os Jogos mesmo após o massacre, colaborando para a construção da ideia de que, para essa instituição, os interesses comerciais vinculados à escala global do evento, tornado espetáculo, se sobrepõe a violação dos direitos humanos.

Rúbio (2010), ao estudar os principais aspectos dos Jogos Olímpicos no século XX, denomina o período entre 1948 e 1984 como a "fase dos conflitos". A autora apresenta diversos exemplos de conflitos que tiveram como palco as edições dos Jogos Olímpicos: desde a já citada disputa ideológica entre EUA e URSS, que culminou com o boicote dos países capitalistas às Olimpíadas de Moscou (URSS), em 1980, com a respectiva resposta dada pelos soviéticos e pelos países socialistas nas Olimpíadas de Los Angeles, em 1984; passando pelas manifestações antirracismo realizadas nos Jogos da Cidade do México, quando dois atletas negros estadunidenses, Tommie Smith e John Carlos, acabaram banidos das competições esportivas ao fazerem o gesto dos Panteras Negras, símbolo da luta contra o racismo nos EUA, após o recebimento de suas medalhas. Na ocasião o COI alegou que o evento não era lugar para a política, porém, não forneceu o mesmo tratamento à ginasta tcheca, Vera Caslavská, que se recusou a 
cumprimentar, no momento de recebimento de medalhas, as suas adversárias soviéticas, em protesto à invasão de Praga. (RÚBIO, 2010)

Nesse contexto, é importante lembrar também a ação do grupo terrorista palestino Setembro Negro que sequestrou atletas israelenses nos Jogos Olímpicos de Munique (Alemanha), em 1972. A ação terminou com a morte de 11 atletas israelenses, 5 terroristas, 1 policial e 1 piloto, gerando uma comoção internacional. No entanto, o COI, mesmo assim, decidiu sustentar o evento, após guardar 1 dia de luto em homenagem às vítimas. (RÚBIO, 2010)

Os fatos relatados demonstram a dimensão de megaevento global que os Jogos Olímpicos foram adquirindo na segunda metade do século XX. A escolha do evento para a realização de manifestações políticas associa-se à capacidade de visibilidade que o evento poderia conferir às disputas entre EUA e URSS, às ações terroristas ou de movimentos antirracismo, conforme os exemplos citados.

A dimensão global do megaevento também é ressaltada pelo número cada vez maior de países participantes, bem como pela ascensão dos valores pagos pelos direitos de transmissão dos Jogos. Conforme demostrado no Figura 3, na década de 1980 houve um expressivo aumento dos valores pagos pelo direito de transmissão, passando de US\$ 88 milhões em 1980 para US\$286,9 milhões, em 1984, até atingir a cifra de US\$1,74 bilhões, em 2008 (INTERNATIONAL OLYMPIC COMMITTEE, 2012). Esse crescimento astronômico está associado à estratégia de mercantilização dos Jogos adotada pela gestão de Juan Antonio Samaranch na presidência do COI. O mandato de Samarach (1980- 2001), só foi menor que o do Barão de Coubertin (1896-1925), idealizador dos Jogos. 


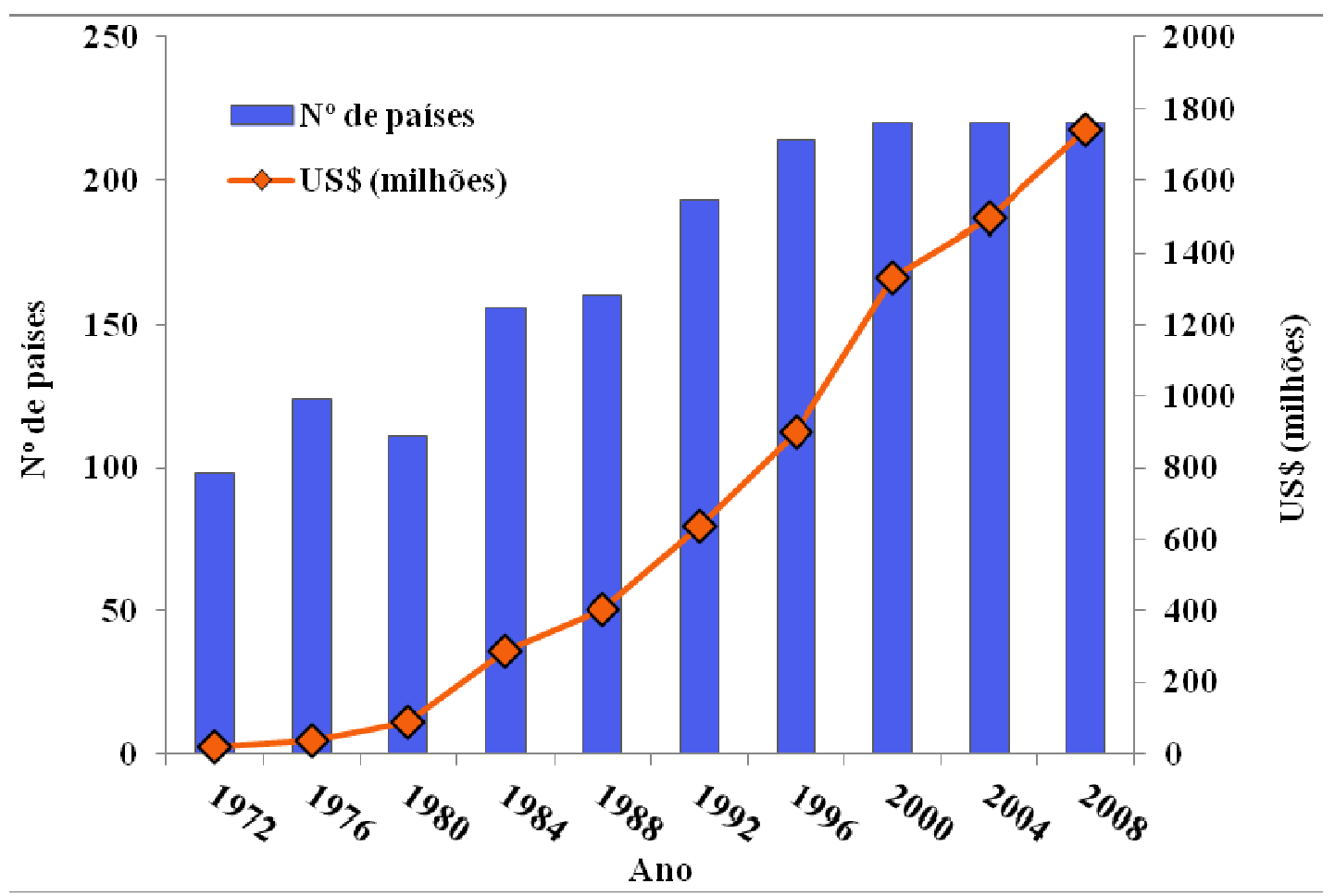

Figura 3 - Gráfico do número de países que receberam cobertura televisiva dos Jogos Olímpicos e do valor das receitas dos direitos de transmissão no período de 1972 a 2008 Fonte dos dados: International Olympic Committee, 2012. Organizado pelo autor.

Sua primeira iniciativa na direção da mercantilização das Olimpíadas foi a realização do Tratado de Nairobi, em 1981, tendo em vista o estabelecimento do direito de propriedade sobre os símbolos olímpicos (cinco anéis, bandeira, lema, hino, designações, emblemas, chama, tocha, identificações como "Jogos Olímpicos", entre outros). Esse tratado marcou o reconhecimento do potencial econômico das propriedades olímpicas, garantindo o controle do seu uso ao COI (ALMEIDA et al., 2011).

Em 1985, foi criado o programa The Olympic Partners (Os Parceiros Olímpicos), conhecido pela sigla TOP. A ideia do programa era negociar de uma só vez, para um conjunto de patrocinadores, os direitos à exclusividade de patrocínio dos Jogos de Verão e de Inverno, bem como de marketing sobre os símbolos olímpicos, por um período de quatro anos. A receita do primeiro quadriênio do programa (1985-1988) foi de US\$ 96 milhões, já no último foi (2009-2012) foi de 957 milhões (INTERNATIONAL OLYMPIC COMMITTEE, 2012) 
As onze empresas que atualmente participam do programa TOP são: Coca-Cola, Acer, Atos, Dow, GE, McDonald's, Ômega, Panasonic, Procter \& Gamble, Samsung e Visa. Dentre os patrocinadores mencionados, destaque deve ser dado à Coca-Cola, que participou de todas as sete edições do programa TOP e é patrocinadora das Olimpíadas desde os Jogos de Amsterdam (Países Baixos), em 1928, por mais que possa ser questionável a relação entre uma empresa de refrigerantes e a prática esportiva e os ideais de vida saudável a ela associados. O mesmo questionamento também pode ser levantado para o patrocínio da cadeia de fast food McDonald's. A partir desses dados, pode-se inferir que, mais que valores e ética associados ao esporte olímpico, o imperativo passa a ser sua transformação em mercadoria.

O COI ao transformar os Jogos Olímpicos em propriedade, simultaneamente também os transformou em produto para as empresas que querem associar suas marcas aos signos e atributos olímpicos, tais como a vitória, a competitividade, o prazer, a força, a superação, entre outros. Desde os Jogos de Roma, em 1960, com o início das transmissões televisivas, que diversas empresas buscaram associar suas marcas aos atletas campeões olímpicos.

Dessa forma, a década de 1980 ficou marcada pelo fim do amadorismo, idealizado pelo Barão de Coubertin, como condição para a participação nos Jogos Olímpicos, e pelo início de uma "fase profissional", na qual o esporte se transformou em meio de vida para os atletas e os campeões foram transformados em mercadorias a serem vendidas em todo o planeta. Rúbio afirma que "o atleta profissional não é apenas aquele que tem ganhos financeiros pelo seu trabalho, ele é também a representação vitoriosa de marcas e produtos que querem estar vinculados à vitória, à conquista de resultados.” (RÚBIO, 2010, p.66)

Nesse sentido, os Jogos Olímpicos de Los Angeles (1984) foram o marco histórico do início dessa "fase profissional" do esporte olímpico, que se estende até os dias atuais, e também do fortalecimento da relação, cada vez mais indissociável, entre os interesses empresariais e a preparação e a realização desse evento.

Se na edição de Montreal (Canadá), em 1976, o governo local teve um prejuízo de aproximadamente US\$ 1,7 bilhão, que foram revertidos em impostos à população quebecoise que só terminaram de ser pagos no ano 2000 (RÚBIO, 2010), na edição de 
Los Angeles, em 1984, com um Comitê Organizador Local composto basicamente por empresários, e a quase nula participação do governo estadunidense, o resultado final foi um evento altamente lucrativo que ficou conhecido com os "jogos capitalistas" (MASCARENHAS, 2011).

Cabe ressaltar que os Jogos de Moscou (URSS), em 1980, haviam sido realizados sob o regime socialista, portanto, sob outro parâmetro de comparação. Apesar da crise que já se instaurava no regime socialista, nas Olimpíadas, os soviéticos mostraram ao mundo grandes atletas e também grande capacidade de organização. Ao considerar as transformações urbanas, foi exibido um modelo de urbanismo funcional diretamente associado ao sistema socialista e um projeto de vila olímpica que seria o ápice da política de habitações populares, com a construção de 18 prédios de 16 andares (MASCARENHAS, 2011).

As edições posteriores aos Jogos Olímpicos de Los Angeles foram marcadas pela exploração econômica das Olimpíadas em diversos aspectos, tais como: mídia, publicidade, construção civil, mercado imobiliário, consultorias especializadas, entre outros. Mas, também foram caracterizadas pelo aumento dos impactos sociais e ambientais, principalmente aqueles relacionados às populações mais pobres das cidadessede. (MELO \& GAFFNEY, 2010)

Nas Olimpíadas de Seul (Coreia do Sul), em 1988, o governo sul-coreano promoveu a imagem de um país moderno, construindo instalações desportivas de última geração e divulgando internacionalmente marcas das suas principais empresas. Porém, simultaneamente, as obras para a realização do evento foram responsáveis pela remoção de 720.000 pessoas, totalizando $9 \%$ da população da cidade. Isso sem considerar o elevado contingente populacional que foi obrigado a trocar de residência devido à elevação dos preços nas áreas onde ocorreram as intervenções urbanísticas para a realização dos Jogos (MELO \& GAFFNEY, 2010).

Melo \& Gaffney (2010) reforçam que esses problemas se repetiram, com algumas variações, nas edições posteriores. Os autores revelam ainda que mesmo no caso dos Jogos de Barcelona (Espanha), em 1992, onde menos de 0,15\% da população foi removida em decorrência das obras para os Jogos, ocorreram remoções indiretas em 
decorrência do aumento de mais de $150 \%$ dos preços das moradias. A consequência desse processo foi o deslocamento de parte da população para as periferias.

Tanto os Jogos de Barcelona (1992) quanto os de Seul (1988) foram realizados a partir da parceria entre o setor público e o setor privado. Em ambos os casos, expressivas quantidades de verbas foram gastas em projetos urbanísticos que redefiniram centralidades e se constituíram em marcos na evolução urbana. As Vilas Olímpicas construídas para a realização desses Jogos também apresentaram uma nova concepção, não mais associadas às classes populares, mas, sim, ao seu uso pelas classes médias, revelando também os crescentes interesses empresariais na organização dos Jogos.

$\mathrm{Na}$ edição de 1996, o movimento olímpico comemorava um século de existência. Apesar da candidatura de Atenas e do simbolismo da data associado à cidade, os Jogos foram realizados em Atlanta, sede da Coca-Cola, que, conforme descrito anteriormente, era o patrocinador mais antigo dos Jogos. A escolha da cidadesede para essa edição dos Jogos evidencia o poderio das grandes empresas patrocinadoras das Olimpíadas frente aos valores pregados pelo movimento olímpico.

A edição de 1996 fortaleceu a parceria público-privada como modelo de organização dos Jogos. A cidade de Atlanta não dispunha de instalações esportivas em quantidade e qualidade exigida para a realização do evento, o que demandou a participação do poder público e não permitiu a repetição do modelo adotado em Los Angeles em 1984 (MASCARENHAS, 2011).

Quatro anos mais tarde, em Sidney (Austrália), os recursos públicos novamente foram fundamentais para a realização das Olimpíadas. A organização buscou construir a ideia de Jogos Ecológicos, seguindo uma série de recomendações do Greenpeace, tais como: a reciclagem de lixo olímpico, a utilização de energia solar para os estádios, o uso de trem, entre outros (DARIDO, 2000). A Vila Olímpica alcançou o maior grau de sofisticação do olimpismo, contou com dois mil imóveis de alto padrão em sofisticado bairro litorâneo construído utilizando diversas tecnologias relacionadas ao meio ambiente (MASCARENHAS, 2011). Ao final, o Greenpeace admitiu avanços na organização dos Jogos, mas questionou que o governo não cumpriu com a promessa de 
descontaminação da baía de Homebush e os riscos ambientais continuaram a existir para os habitantes que viviam na área.

Depois de ter sido preterida por Atlanta para realizar a edição comemorativa de 100 anos do movimento olímpico, Atenas (Grécia) foi escolhida para sediar a primeira edição dos Jogos Olímpicos do século XXI. Com as Olimpíadas os governantes buscaram simultaneamente reforçar as raízes de "berço da civilização ocidental", que conferem distinção simbólica à cidade, e também construir uma paisagem moderna que promovesse uma imagem de cidade global (STAVRIDES, 2008). Para tanto, foram construídos projetos de arquitetura espetaculares, como o Estádio Olímpico, modernizou-se o sistema de transporte, construindo um novo aeroporto, expandindo o metrô e construindo autoestradas.

Entretanto, os gastos excessivos para a realização do evento levantaram muitos questionamentos, que continuam até os dias atuais, inclusive relacionando a atual crise da econômica do país à realização dos Jogos. Stavrides (2008) aponta ainda que nos Jogos de Atenas foi instituído um tipo de "estado de emergência", a partir do qual, tendo em vista o sucesso do evento e a imagem da cidade, foi permitida a violação de leis de uso do solo e de direitos trabalhistas.

Em 2008, os Jogos Olímpicos foram realizados na cidade de Pequim. O poderio econômico chinês, no início do século XXI, credenciou o país a sediar os Jogos e a exibir para o mundo o progresso técnico e a capacidade organizativa do seu governo. Foram feitos investimentos de mais de US\$ 34 bilhões que produziram uma verdadeira revolução urbanística, com a construção de instalações esportivas, de avenidas, de condomínios de luxo, a expansão do metrô e do aeroporto. Esse processo acarretou na remoção de quase $10 \%$ da população da cidade, totalizando 1.250 .000 moradores. (MASCARENHAS et al., 2008; MELO \& GAFFNEY, 2010)

Para consolidar sua imagem como superpotência o governo chinês construiu dois ícones arquitetônicos no Parque Olímpico: o Estádio Nacional (Ninho do Pássaro) e o Centro Nacional de Esportes Aquáticos (Cubo D'água). Outro exemplo foi o investimento na formação de atletas para o sucesso no quadro de medalhas, os chineses conseguiram atingir a marca de 51 medalhas de ouro, feito só alcançado anteriormente 
por URSS (1972, 1980 e 1988), EUA (1904 e 1984) e Inglaterra (1908), e garantiram o primeiro lugar isolado na competição.

\section{Considerações finais}

$\mathrm{Na}$ análise histórica dos Jogos Olímpicos, aqui desenvolvida, destaca-se a transformação das Olimpíadas em um megaevento esportivo, cada vez mais marcado pelo domínio dos interesses empresariais no planejamento, na organização e na realização dos Jogos, bem como na mercantilização dos signos associados ao evento. Nesse sentido, o início das transmissões televisivas a partir dos Jogos de Roma, em 1960, bem como as ações implementadas por Samarach na década de 1980, como o estabelecimento do direito à propriedade dos símbolos olímpicos e a criação do programa “Os Parceiros Olímpicos” (TOP), foram marcos desse processo.

Paralelamente a essas transformações em direção ao empresariamento e, consequentemente, à mercantilização dos Jogos Olímpicos, há também a introdução de uma nova forma de governança das cidades: o empreendedorismo urbano, que considera os Jogos como uma oportunidade de realização de grandes transformações urbanísticas e de reposicionamento da cidade no mundo, que passaria a ter sua imagem atrelada aos signos olímpicos de competitividade, saúde, vigor, etc.

Dessa forma, o empreendedorismo urbano tem como uma de suas principais características a realização de intervenções urbanas capazes de atrair investidores, entre as quais destacam-se as de grande porte e os megaeventos, como, por exemplo, os Jogos Olímpicos. Essas intervenções subordinam a gestão e a produção do espaço urbano aos circuitos do capitalismo globalizado, na construção de um discurso que enuncia a meta de tornar a "cidade ganhadora" na "guerra dos lugares", na atração de investimentos e turistas internacionais, numa perspectiva em que a cidade é vista simultaneamente empresa e mercadoria.

Por outro lado, essa experiência de governança empreendedorista e de realização de megaeventos esportivos, que se tornaram paradigmáticas nas últimas décadas do século XX apresentaram também violações no direito à cidade, expressos nos casos de remoções das populações residentes em áreas de intervenções urbanísticas, nos 
desalojados indiretamente pelo aumento significativo do valor do solo urbano nas cidades-sede e também na repressão aos movimentos sociais.

\section{Nota}

Esse artigo está relacionado às discussões apresentadas na dissertação de mestrado do autor, desenvolvida no programa de Pós-graduação em Engenharia Urbana da UFRJ. Tal trabalho está inserido no âmbito da pesquisa "Metropolização e Megaeventos", financiada pela FINEP. O autor agradece ao seu orientador, Orlando Alves dos Santos Junior, pelas valiosas sugestões feitas no processo de elaboração desse trabalho.

\section{Referências}

ALMEIDA, Bárbara Schausteck de; MEZZADRI, Fernando Marinho; MARCHI JÚNIOR, Wanderley. Considerações sociais e simbólicas sobre sedes de megaeventos esportivos. Motrivivência, ano 21, n. 32/33, p.178-192, jun./dez. 2009.

ALMEIDA, Bárbara Schausteck de; VLASTUIN, Juliana; MARCHI JÚNIOR, Wanderley. Proteção à marca versus liberdade de expressão? Discursos emergentes a partir dos megaeventos esportivos no Brasil. Esporte e Sociedade, ano 6, n.18, set. 2011.

ARANTES, Otília. Uma estratégia fatal: a cultura nas novas gestões urbanas. In: ARANTES, Otília; VAINER, Carlos; MARICATO, Ermínia (Org.). A cidade do pensamento único: desmanchando consensos. $2^{\mathrm{A}}$ ed. Petrópolis: Vozes, 2000. 192p. $11-74$

DARIDO, Suraya Cristina. As Olimpíadas de Sydney, o desempenho do Brasil e algumas implicações pedagógicas. Motriz, Revista de Educação Física, Rio Claro, v. 6 , n. 2, p.101-105, jul./dez. 2000.

ESSEX, Stephen \& CHALKLEY, Brian. Megasporting events in urban and regional policy: a history of the Winter Olympics. Planning Perspectives, v. 19, n. 2, p. 201232, abr. 2004.

FIORI. José Luís. 60 lições dos 90: uma década de neoliberalismo. Rio de Janeiro: Record, 2001. 236p.

FIORI. José Luís. Governabilidade, por que e qual?. Teoria e Debate, São Paulo, n. 29, jun./ago. 1995.

INTERNACIONAL OLYMPIC COMMITTEE. Marketing fact File. Lausanne: IOC, 2012. 42p.

LA DOCUMENTATION FRANCAISE. Questions internationales: le sport dans la mondialisation, n.44, juil. 2010.

\footnotetext{
Geo UERJ - Ano $15, \mathrm{n}^{\circ} .24$, v. $1,1^{\circ}$ semestre de 2013 p. 37-60

ISSN: 1415-7543 E-ISSN: 1981-9021

http://www.e-publicacoes.uerj.br/index.php/geouerj
} 
MASCARENHAS, G. A cidade e os grandes eventos olímpicos: uma geografia para quem?. Lecturas Educación Física y Deportes, Buenos Aires, año 8, n. 78, 2004.

MASCARENHAS, Gilmar; PONTES, Jéferson Alexandre; NEVES, Juliana Cristina Queiroz das; BRAZ, Leandro de Souza; SIMEONE, Leonardo Maia. Pequim 2008: uma primeira avaliação sobre território, cidadania e legados. Lecturas Educación Física y Deportes, Buenos Aires, año 13, n. 124, set. 2008.

MASCARENHAS, Gilmar. Desenvolvimento urbano e grandes eventos esportivos: o legado olímpico nas cidades. In: MASCARENHAS, Gilmar; BIENESTEIN, Glauco; SÁNCHEZ, Fernanda (Org.). O jogo continua: megaeventos esportivos e cidade. Rio de Janeiro: EdUERJ, 2011. 302p. p.27-39

MELO, Erick Silva Omena de \& GAFFNEY, Christopher. Mega-eventos esportivos no Brasil: uma perspectiva sobre futuras transformações e conflitos urbanos. Rio de Janeiro: FASE, 2010. 44p.

RAEDER, Sávio. Conflitos no ordenamento territorial em grandes eventos esportivos. In: MASCARENHAS, Gilmar; BIENESTEIN, Glauco; SÁNCHEZ, Fernanda (Org.). O jogo continua: megaeventos esportivos e cidade. Rio de Janeiro: EdUERJ, 2011. 302p. p.259-286

RIBEIRO, Ana Clara Torres. Acumulação primitiva de capital simbólico: sob a inspiração do Rio de Janeiro. In: JEUDY, Henri-Pierre \& JACQUES, Paola Berenstein (Org.). Corpos e cenários urbanos: territórios urbanos e políticas culturais. Salvador: EdUFBA, 2006. 182p. p.39-50

RIBEIRO, Luiz César Queiróz \& SANTOS JUNIOR, Orlando Alves dos. Desafios da questão urbana. Le Monde Diplomatique Brasil, ano 4, n. 45, p. 4-5, abr. 2011.

RUBIO, Kátia. Jogos Olímpicos da Era Moderna: uma proposta de periodização. Rev. bras. Educ. Fís. Esporte, São Paulo, v.24, n.1, p.55-68, jan./mar. 2010.

SÁNCHEZ, Fernanda; BIENENSTEIN, Glauco; CANTO, Bárbara L.; GUTERMAN, Bruna da Cunha; BENEDICTO, Danielle Barros de M.; PICINATTO, Leonardo. Produção de sentido e produção do espaço: convergências discursivas nos grandes projetos urbanos. Revista Paranaense de Desenvolvimento, Curitiba, n.107, p.39-56, jul./dez. 2004.

SANTOS JUNIOR, Orlando Alves. Democracia e governo local: dilemas da reforma municipal no Brasil. Rio de Janeiro: REVAN/FASE, 2001. 248p.

SANTOS JUNIOR, Orlando Alves dos \& SANTOS, Mauro Rego Monteiro dos. Megaeventos e o direito à moradia: questões e reflexões a partir do contexto do Rio de Janeiro. Rio de Janeiro: UFRJ / Observatório das Metrópoles: 2011. 20p. (mimeo.)

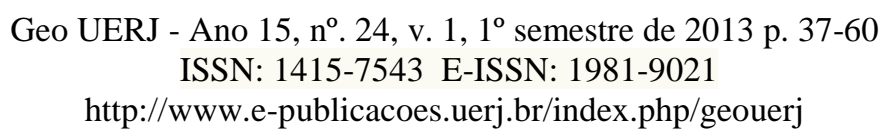


STAVRIDES, Stavros. Urban Identities: Beyond the Regional and the Global: the Case of Athens. In: AL-QAWASMI, Jamal; MAHMOUD Abdesselem; DJERBI, Ali (Org.) Regional Architecture and Identity in the Age of Globalization. Tunis: CSAAR, 2008. p. 577-588.

VAINER, Carlos B. Pátria, empresa e mercadoria: notas sobre a estratégia discursiva do planejamento. In: ARANTES, Otília; VAINER, Carlos; MARICATO, Ermínia (Org.). $A$ cidade do pensamento único: desmanchando consensos. $2^{\mathrm{A}}$ ed. Petrópolis: Vozes, 2000. 192p. 75-103.

Artigo recebido para publicação em março de 2013.

Artigo aceito para publicação em maio de 2013. 